\title{
Hierarchical Leisure Constraints on Leisure Motivation and Participation among Security Agent
}

\author{
Kyong-Sik Kim \\ Dept. of Sport and Leisure Studies \\ Hoseo University, A-san, Chung-nam, Korea \\ Young-Man Park \\ Dept. of Police and Security Service \\ Yeo-ju Institute of Technology, Yeo-ju, Gyeong-gi, Korea
}

\begin{abstract}
This research looks close the effect of security agent's hierarchical leisure constraint on the leisure motivation and participation based on the Jackson's Model of the hierarchical leisure constraints. This research selected 420 people for sampling, designating security agents who work for security companies located in Seoul in 2009 at present as subjects by utilizing purposive sampling method, but the number of sampling used for ultimate analysis is 356. In this research, reliability analysis's and structural equation modeling's Maximum Likelihood method are used to prove the reliability and validity of questionnaire. By using these research method and procedures, the conclusion of this research is as following. First, intra-personal leisure constraint was affected by interpersonal, structural leisure constraint. Second, leisure motivation was affected negatively by leisure constraint. Third, leisure participation was affected positively by leisure motivation. Synthesizing all things referred above, leisure constraint was affected by inter-personal, structural leisure constraint, and in turn, leisure motivation and leisure participation were affected by its effects. It turned out that leisure motivation has a meaningful effect on leisure participation through leisure participation and adjusting process.
\end{abstract}

Keywords: Hierarchical Leisure Constraints, Leisure Motivation, Leisure Participation, Security Industry

\section{INTRODUCTION}

In modern society, the increase of several terrorist attacks and crimes have caused bodily harms and damages on properties along with psychological uneasiness, and the limit of human resources and material resources such as human force, budget, equipment as the means for public expenses for security service, has led to a growth of the development of private security industry. Despite the steep quantitative growth of security industry, the qualitative growth falls behind it. Security agents can be regarded as the pillars of the security organization that largely contributes to the public interest by taking part in the tasks such as preventing physical harm and damage on properties. Nonetheless, security industry is still dotted with various problems that are caused by small businesses such as the falling of social status along with employment instability and turnover problems caused by low payment and inadequate welfare system. The lowering morale and excessive stress resulted from the system of social welfare and the decline of social status have become the main factors

\footnotetext{
*Corresponding author.E-mail : kks7@office.hoseo.ac.kr Manuscript received Feb. 09, 2010 ; accepted Jun. 16, 2010
}

that deter the qualitative growth of security industry[1]. It is desirable that these stress problems are solved by the refreshment and revitalization through the participation in healthy leisure activities. However, the fact of life is that the security agents not being able to participate in leisure activities due to the constraint on taking part in those activities because of the work routine. Accordingly, the constraint of participating in leisure activities also turns out to be the factor that negatively affects the welfare of the security agents.

Therefore, this study which focuses on security agents starts from the assumption that the constraint on leisure due to the work will affect the participation and motivation toward leisure activities. As most of the previous studies regarding the leisure constrain and leisure motivation, however, have only dealt with the relationship of leisure constraint and participation motivation, they could not formalize the result verification for the participation itself after the arouse of leisure motivation in diachronic perspective, or they proceeded fragmentary studies that were limited to the motives of leisure activities which led to the insufficient results in re-proving the positively verifying the relationship between the hectic routine of the modern people and the leisure, and the importance of leisure[2]. That is 
to say, in order to overcome the limitations of previous studies that could not verify the meaning of productive activities on the level of redistribution of idle time separated from work which is the most significant reason of leisure, formalizing the relationship between the generation of leisure constraint and motivation, and the participation, is the purpose of this study.

The participation in leisure activities plays a meaningful role in the qualitative improvement of life, promotion of health, and self-realization. In spite of the importance of the leisure activities, the chances of leisure participation for security agents are relatively slim than ordinary people due to the environmental aspects and business features. This can be attributed to the impediments caused by several leisure constraints on leisure participation. Leisure constraints can be classified to three types: personal factors, interpersonal factors, and structural factors; and the constraint can be assumed as hierarchical leisure constraint that is emphasized as the factor affecting the leisure preference and participation[3],[4]. When facing constraints such as interpersonal or structural constraint that make the compromise impossible or hard to achieve, hierarchical leisure constraint effectively performs the function in precedential intrapersonal constraint, by controlling the desire to participate in the leisure activities through the feedback regarding the constraint. Hierarchical leisure constraints refer to flow of sequential and temporal constraints that participants are faced in leisure activities. Lee and Park[3] examined hierarchical structure of leisure constraints in research on leisure constraints, leisure motivation and leisure participation in terms of ecology. Established studies of leisure constraints did not assume a causal relationship between submeasure variables of leisure constraints but recent some studies [3][4] reported that there exists hierarchical leisure constraint structure by temporal flow in leisure constraints. Leisure activity participants first undergo structural constraints such as leisure costs and working hours and interpersonal constraints such as absence of leisure companion and then experience that internal constraints of the individual such as peripheral awareness and lack of energy are deepened by these constraints. Structural constraints and intra personal constraints precede internal constraints of the individual and these leisure constraint structures influence leisure motivation and participation hierarchically. Unlike other countries, in Korea, some scholars [26],[27],[28],[29] from the field of tourism proved the usefulness of theory by introducing hierarchical theory but related research is insufficient compared to foreign countries.

Participation in leisure activities can be said to be the process of compromise accomplished by the interaction between the constraint and the motivation[5]. Crawford, Jackson and Godbey[4] who asserted that the leisure constraint consecutively affects the preference and participation regarding certain types of leisure activities, suggested the model of balance after adding the role of compromise process and participation motivation on leisure constraint. Crawford also explained the reasons for a security agent not desiring to participate in leisure activities, reasons for he/she wants to take part in but cannot, and the state that he/she being dissatisfied with the leisure activities he/she participating in. These suggestions are the ones that introduced the notion and the role of the motivation in leisure constraints for the first time. According to Crawford, the participation in the leisure activities is the result of the successful compromise regarding leisure constraint, and the compromise and the result of the compromise both depend on the relative size of the motivation and constraint and their interactions[3],[6]. This can be seen as the result that verifies the role of leisure motivation in the relationship of leisure constraint and participation.

According to Stodolska[7], leisure motivation plays an important role in the hierarchical model of leisure constraint. Leisure motivation can be regarded as the conscious, as well as the unconscious reason for a person to participate in a certain leisure activity. That is to say, there is the internal motivation that pursues excitement and happiness through leisure activities; there is the external motivation that intends to receive compensation, and the amotivation that don't get count on the compensation or things through the participation.

Meanwhile, the notion of motivation has not gained critical attention in the field of leisure constraint research. However the study of Carroll and Alexandris[8] and the qualitative study of Stodolska[7] asserted that the motivation plays an important role in the hierarchical model of leisure constraint, and strongly proposed that it is needed to investigate the role of the motivation in the constraint and leisure participation[3].

Regarding this context, the reports from Lee and Park[3], and Raymore[9] that the leisure constraint has a meaningful influence on the leisure motivation and the participation of leisure activities, are supporting the validity of this thesis.

Like this, it is obvious that despite the relation among leisure constraint, leisure motivation and leisure participation, the systematical studies toward those subjects are being insufficient, and the studies of security agents are almost nonexistent.

Therefore, this study intends to emphasize the importance of the security agents' participation in leisure activities, to accumulate the empirical data in the security sector, and to suggest the strategic data on establishing the philosophical value, by analyzing and investigating the relations of the hierarchical leisure constraint, leisure motivation and participation. For this purpose, this study starts by setting up the structural model regarding the security agents' hierarchical leisure constraint, leisure motivation and participation, following by the verification of reality adaptability, and investigating the direct and indirect causal relationship among the variations that are included in the model.

\section{STUDY MODEL AND ASSUMPTION}

\subsection{Study Model}

This study set up the study model based upon the theoretical assumption and previous study result, focusing on the security agents' hierarchical leisure constraint, leisure motivation and the variations regarding the participation as follows. 


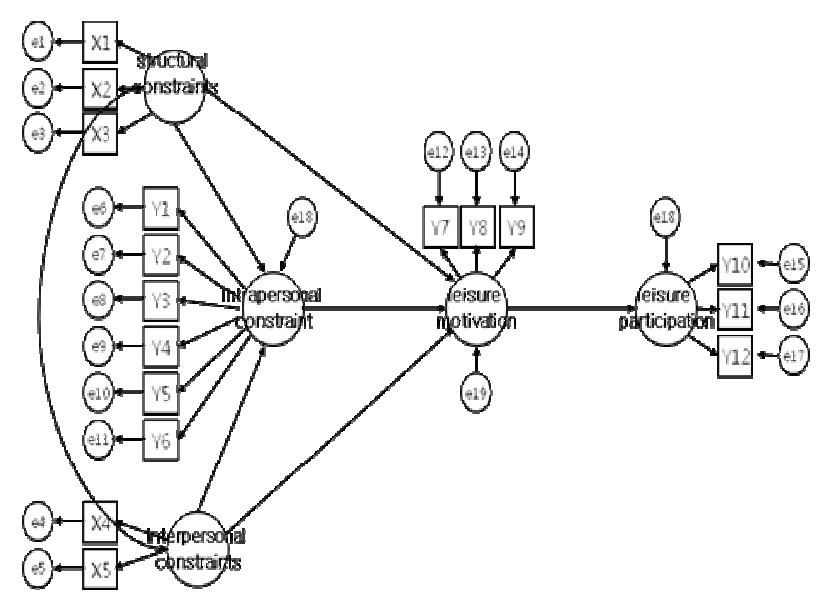

Fig. 1. The structural model of the hierarchical leisure constraint of security agents, leisure motivation, and participation.

According to Fig. 1 the hierarchical leisure constraint and leisure motivation of the security agents are assumed to affect the leisure participation. The definition of extrinsic variable and intrinsic variable regarding the measurement structure of structural model of the effect of the security agents' hierarchical leisure constraint on the leisure motivation and participation is shown in table. 1.

Table. 1. The explanation of the model

\begin{tabular}{|c|c|c|}
\hline Section & $\begin{array}{l}\text { Theoretical } \\
\text { Variable }\end{array}$ & Measurement Variable \\
\hline \multirow{2}{*}{$\begin{array}{l}\text { Endoge } \\
\text { neous } \\
\text { Variable }\end{array}$} & $\begin{array}{l}\text { Structural } \\
\text { constraints }\end{array}$ & $\begin{array}{l}\text { Because of leisure } \operatorname{cost}(\mathrm{x} 1) \\
\text { Too busy working(x2) } \\
\text { Participating by others' } \\
\text { evaluation(x3) }\end{array}$ \\
\hline & $\begin{array}{c}\text { Interpersonal } \\
\text { constraints }\end{array}$ & $\begin{array}{l}\text { No partner for leisure } \\
\text { activity }(\mathrm{x} 4) \text {, } \\
\text { Too far distant with partner(x5) }\end{array}$ \\
\hline \multirow[t]{3}{*}{$\begin{array}{l}\text { Exogen } \\
\text { eous } \\
\text { Variable }\end{array}$} & $\begin{array}{c}\text { Intrapersonal } \\
\text { constraints }\end{array}$ & $\begin{array}{l}\text { Unfamiliar of using public } \\
\text { locker room(y1), } \\
\text { Unfamiliar of leisure with others } \\
\text { (y2), } \\
\text { Avoid crowded facility(y3), } \\
\text { Too much conscious of others' } \\
\text { eye(y4), } \\
\text { Energy lack for enjoying } \\
\text { leisure(y5), } \\
\text { Physical condition does not } \\
\text { help(y6) }\end{array}$ \\
\hline & $\begin{array}{c}\text { Leisure } \\
\text { motivation }\end{array}$ & $\begin{array}{l}\text { amotivation(y7), } \\
\text { extrinsic motivation(y8), } \\
\text { intrinsic motivation(y9) }\end{array}$ \\
\hline & $\begin{array}{c}\text { Leisure } \\
\text { participation }\end{array}$ & $\begin{array}{l}\text { Participation frequency(y10), } \\
\text { Participation duration(y11), } \\
\text { Participation burglar(y12) }\end{array}$ \\
\hline
\end{tabular}

\subsection{Study Hypothesis}

In order to investigate the influence of the security agents' hierarchical leisure constraint on the leisure motivation and participation, the following assumptive propositions will be set up and verified.

Hypothesis 1. The structural leisure constraint of a security agent will affect the personal leisure constraint.

Hypothesis 2. The intrapersonal leisure constraint of a security agent will affect the personal leisure constraint.

Hypothesis 3 . The structural leisure constraint of the security agents will affect the leisure motivation.

Hypothesis 4. The intrapersonal leisure constraint of the security agents will affect the leisure motivation.

Hypothesis 5. The personal leisure constraint of the security agents will affect the leisure motivation.

Hypothesis 6 . The leisure motivation of the security agents will affect the leisure participation.

\section{STUDY METHOD}

\subsection{Study Subject}

The subjects for this study were the private security guard working in Seoul-based private security firms in 2009, and were selected by using the purposive sampling method. The reason for limiting the subjects as those working in Seoul is because there are relatively more large firms and more demands for security, and it gives them the representativeness. The demographic characteristics of the subjects are displayed in table. 2.

\subsection{Subject}

This study got samples using purposive sampling method after selecting private security agents at security enterprises in 2009 , Seoul. The reason restricting research subjects in Seoul is because there exist more bigger enterprises and demand of security if higher than local enterprises. There are 420 subjects sampled in this research this 14 enterprises which have over 30 employees rslistered in National Police Agency. 30 questionnaires were distributed in each enterprise, total 420 . 387 samples of those were collected. 31 samples with poor contents, unreliable data, or outliers were excluded, and 356 samples were used in final analysis.

Table 2. General characteristics of the respondents

\begin{tabular}{|c|c|c|c|}
\hline \multicolumn{2}{|c|}{ Assortment } & $\begin{array}{c}\text { Peoples } \\
(\mathrm{N})\end{array}$ & $\begin{array}{c}\text { Percent } \\
(\%)\end{array}$ \\
\hline \multirow{3}{*}{ Gender } & Males & 293 & 82.3 \\
\cline { 2 - 4 } & Females & 63 & 17.7 \\
\hline \multirow{3}{*}{ Age } & Less than 25 years old & 144 & 40.4 \\
\cline { 2 - 4 } & 26years old-30years old & 146 & 41.0 \\
\cline { 2 - 4 } & 31years old-35years old & 32 & 9.0 \\
\cline { 2 - 4 } & More than 36years old & 34 & 9.6 \\
\hline \multirow{3}{*}{ Scholarship } & $\begin{array}{c}\text { Less than high-school } \\
\text { graduate }\end{array}$ & 111 & 31.2 \\
\cline { 2 - 4 } & College graduate & 145 & 40.7 \\
\hline
\end{tabular}




\begin{tabular}{|c|c|c|c|}
\hline & $\begin{array}{l}\text { More than a university } \\
\text { graduate }\end{array}$ & 100 & 28.1 \\
\hline \multirow{3}{*}{$\begin{array}{l}\text { Service } \\
\text { career }\end{array}$} & Less 1 year & 171 & 48.0 \\
\hline & 1 year $\sim 3$ year & 111 & 31.2 \\
\hline & More than3 year & 74 & 20.8 \\
\hline \multirow{2}{*}{$\begin{array}{l}\text { Job } \\
\text { level }\end{array}$} & Grudge & 279 & 78.4 \\
\hline & Administrator & 77 & 21.6 \\
\hline \multirow{6}{*}{ Job types } & Institution security & 119 & 33.4 \\
\hline & Body guard & 6 & 18.5 \\
\hline & Electronic Security & 39 & 11.0 \\
\hline & Escort Security & 54 & 15.2 \\
\hline & Special Security & 29 & 8.1 \\
\hline & Etc & 49 & 13.8 \\
\hline \multirow{5}{*}{$\begin{array}{l}\text { Monthly } \\
\text { income }\end{array}$} & Less than 1000000 won & 64 & 18.0 \\
\hline & $1010000-1200000$ won & 89 & 25.0 \\
\hline & $1210000-1400000$ won & 80 & 22.5 \\
\hline & $1410000-1600000$ won & 60 & 16.9 \\
\hline & More than 1610000 & 63 & 17.7 \\
\hline \multirow{2}{*}{$\begin{array}{l}\text { Marriage } \\
\text { presence }\end{array}$} & Single & 301 & 84.6 \\
\hline & Married & 55 & 15.4 \\
\hline \multicolumn{2}{|r|}{ total } & 356 & 100 \\
\hline
\end{tabular}

Total 420 subjects were selected as samples, specifically from the 14 security firms registered in the list of the Nation Police Agency and that possess more than 30 workers. Originally, 420 questionnaires were distributed(30 questionnaires for each of the 14 firms), and 387 samples were collected. Among those questionnaires, 356 were used in the final analysis after excluding the data that were determined to be insufficient and unreliable, and the outlier of 31 .

\subsection{Research instrument}

The questionnaire used in this study is composed of 8 questions of demographic characteristics, 4 questions of leisure activities, 20 questions of leisure motivation, 12 questions of leisure constraints and it is total 44 questions. Demographic traits are composed of Gender, Age, Educational background, Job position, Career, Working condition, Monthly income, and Marital status which are based on previous study of Kim, Kim, and $\mathrm{Kim}[1]$. In questions of leisure participation, frequency, attended duration, and intensity were measured which were used by Kim, Kim, Lee and Kim[10]. And the questions used by Jennifer and Roger[11] were used after modifying it to match the purpose of this study. The questions used by Jung[12] regarding leisure motivation also were modified and complemented, and then applied in the study. The standard of leisure constraints and leisure motivation in questionnaire is composed of 'never(1 point) to always(5 point)' which is Likert 5 point standard. The method of the study consists of questionnaire which can represent variables based on previous research and the result from the meeting with experts. Since the measurement variable of theory variable was made up based on the previous study, it is considered to have little problem with it.

\subsection{The Validity and reliability of the Questionnaire}

In this study, the validity and reliability of the questionnaire was verified by going through the preliminary inspection of the security agents' hierarchical leisure constraint, leisure motivation and participation. Validity shows whether the researcher is accurately measuring the notion and features that correspond his/her original intension. Prior to the verification of structural model of the collected data, the construct validity of the collected data was verified by using confirmatory factor analysis, setting the extraneous variable and endogenous variable as subjects, and through reliability analysis, Cronbch's $\alpha$ value was calculated.

Following table 3 is displaying the analysis result regarding the validity and reliability of the measurement model.

As suggested in table. 3, the maximum likelihood estimation from covariance structure analysis was used to verify the validity of the questionnaire. As a result of factor analysis, extraneous variable showed the level of .586, and the endogenous variable showed the level above .569. The variables regarding leisure constraint and leisure motivation confirmed the multi-dimensional subordinate notion, and leisure participation confirmed the single notion of participation frequency. Variables of leisure participation were excluded from the final analysis, since the participation duration and the intensity marked the level below .40 .

\subsection{Procedure and Data Analysis}

This study adopted judgment sampling method to questionnaire and distributed it to security agents and asked them to answer it by self-administration method. On the process of research, researcher visited selected enterprise and asked for help. Then we explained the purpose of this study and asked them to answer the questionnaire and collected it. Insufficient contents, thought to be unreliable data, and outliers within collected questionnaire were excluded and the rest were used in final analysis. SPSSWIN 16.0 Version and AMOS 6.0 were used for data management and first, conducted factor analysis and reliability analysis for verifying adequacy and reliability. Second, to deduct correlation matrix among variable in structure equation model(SEM), we conducted correlation analysis, and third, to verify adequacy of research model and hypothesis, SEM was used.

Table 3. factor loading of extraneous·endogenous variables by SEM maximum likelihood estimation

\begin{tabular}{|c|c|c|c|c|}
\hline $\begin{array}{c}\text { Composition } \\
\text { Concept }\end{array}$ & $\begin{array}{c}\text { Theoretical } \\
\text { Variable }\end{array}$ & $\begin{array}{c}\text { Standard } \\
\text { value }(\lambda)\end{array}$ & $\begin{array}{c}\text { Measurement } \\
\text { error(e) }\end{array}$ & Cronbach's $\alpha$ \\
\hline Structural & Because og leisure $\operatorname{cost}(\mathrm{x} 1)$ & $.586^{* * *}$ & $.666^{* * *}$ & .621 \\
\hline
\end{tabular}




\begin{tabular}{|c|c|c|c|c|}
\hline \multirow[t]{2}{*}{ constraints } & Too busy working(x2) & $.680 * * *$ & $.538 * * *$ & \\
\hline & Participating by others' evaluation(x3) & $.673 * * *$ & $.706^{* * *}$ & \\
\hline \multirow{2}{*}{$\begin{array}{l}\text { Interpersonal } \\
\text { constraints }\end{array}$} & No partner for leisure activity $(x 4)$ & $.719 * * *$ & $.426 * * *$ & \multirow{2}{*}{.724} \\
\hline & Too far distant with partner(x5) & $.816^{* * *}$ & $.335^{* * *}$ & \\
\hline \multirow{6}{*}{$\begin{array}{l}\text { Intrapersonal } \\
\text { constraints }\end{array}$} & Unfamiliar of using public locker room(y1) & $.681 * * *$ & $.683 * * *$ & \multirow{6}{*}{.830} \\
\hline & Unfamiliar of leisure with others (y2) & $.683 * * *$ & $.579 * * *$ & \\
\hline & Avoid crowded facility(y3) & $.575 * * *$ & $.700 * * *$ & \\
\hline & Too much conscious of others' eye(y4) & $.657 * * *$ & $.613 * * *$ & \\
\hline & Energy lack for enjoying leisure(y5) & $.770 * * *$ & $.600 * * *$ & \\
\hline & Physical condition does not help(y6) & $.712 * * *$ & $.612 * * *$ & \\
\hline \multirow{3}{*}{$\begin{array}{l}\text { Leisure } \\
\text { motivation }\end{array}$} & amotivation(y7), & $.635^{* * *}$ & $.395 * * *$ & .869 \\
\hline & Extrinsic motivation(y8), & $.921 * * *$ & $.151^{* * *}$ & .915 \\
\hline & Intrinsic motivation(y9) & $.609 * * *$ & $.586 * * *$ & .835 \\
\hline \multirow{3}{*}{$\begin{array}{c}\text { Leisure } \\
\text { participation }\end{array}$} & Participation frequency(y10) & $.569 * * *$ & $.625^{* * *}$ & - \\
\hline & Participation duration(y11) & .248 & Delete & \\
\hline & Participation burglar(y12) & .045 & Delete & \\
\hline
\end{tabular}

※ items under standard point of .40 are deleted due to the lack of validity

\section{RESULT ANALYSIS}

\subsection{Verification of Model}

\subsubsection{Verification of Measurement Model}

To verify the adequacy of measurement model, this study conducted confirmatory factor analysis as follows. Fig. 2 shows analyzes result with assuming all correlation among concept variable in SEM.

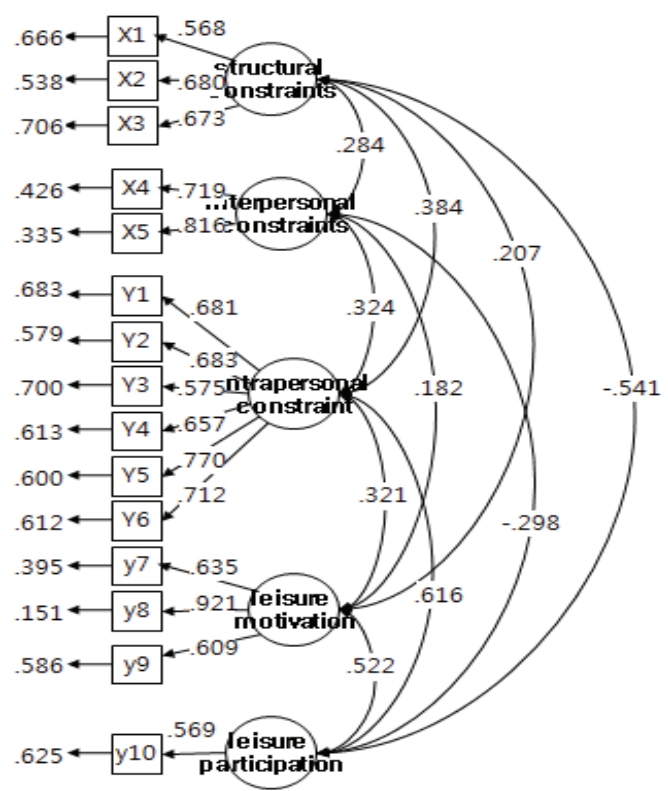

Fig. 2. Measurement model by confirmatory factor analysis

According to Fig. 2, the estimated figure regarding the relations of notion variable and measurement variable of structural constraint, intrapersonal constraint, personal constraint, leisure motivation, and leisure participation exceeds the standard figure of .40. In addition, it is recognizable that the correlation between the theoretical variables is relatively high.

Above table 4 displays the fitness of the measurement model. According to table 6, every Fit Index fulfilled conditions of model except for CMIN value and significance. In this case, $\operatorname{CMIN}\left(\chi^{2}\right) / \mathrm{df}$ value should be considered substitute of CMIN and significance. The figure is $\chi^{2}$ divided by degree of freedom and called Normed $\chi^{2}$. It complements weak point of $\chi^{2}$ and evaluates the inadequacy of model. The figure below 5.0 is judged to be generous adequate rate[13]. Here the point is that even the significant difference exists as the value of $\chi^{2}$ is great and the probable figure is extremely small, the suggested model, in reality, would probably be a desirable model that properly represents the reality, and there can be the case of there conditions of model verification going against. That is why fully depending on the value of $\chi^{2}$ can result in dangerous consequence, so the final conclusion should be drawn after considering other index of correspondence all together[14]. In addition, there is the possibility of the coming out of low probable figure of $\chi^{2}$ like this even when the conditions of model verification are mostly fulfilled; and there can be the dismissal of null hypothesis due to the increased probable figure as it becomes sensitive to even a small difference when the sampling figure is big, although there is not any big difference in covariate coefficient of the structural model and estimated data, and they correspond well. That is its statistical shortcoming. The value of $\chi^{2} / \mathrm{df}$ is 1.879 , and it shows the structural model set up in this study is mostly corresponding to the given data.

\subsubsection{Study Model Verification}

Following table 5 shows the fitness of the model. As 
suggested in table. 5, the model set up in this study reveals significantly high level of CMIN value(279.880), and statistically significant $(\alpha=.000)$, so that it is not applicable in the reality. Moreover, also other index showed dissatisfying level. The reason for unfitness is because estimated coefficient is meaningless, and the covariance among estimation error terms occurs. In explaining the relation among leisure constraint, leisure motivation and leisure participation, it is regarded that the discussing of the relations between the fitness of the model that is inapplicable in reality, and the variables is meaningless[15]. In this case, the model should be developed through the process of revision, supplementation and suggestion on the model[5]. To cultivate the model, this study liberalizes the covariate by linking the error terms with arrows when covariance occurs within them.

\subsubsection{Modification Model and Comparison with Other} Models

This study removed meaningless path(Structural Constraints and Interpersonal Constraints $\rightarrow$ leisure motivation) and liberalized covariance of errors(e1 $\leftrightarrow \mathrm{e} 11, \mathrm{e} 2 \leftrightarrow \mathrm{e} 6, \mathrm{e} 6 \leftrightarrow \mathrm{e} 7$, $\mathrm{e} 7 \leftrightarrow \mathrm{e} 8, \mathrm{e} 12 \leftrightarrow \mathrm{e} 14)$. Table.5 shows validity of updated model.

According to table 6 , this study tries to decide result of model selected with comparing research model and updated model. The result above shows modification model is predominant than research model in aspect of validity. In structure model verification about the influence of hierarchical leisure constraints on leisure motivation and leisure participation is showing null hypothesis(no difference between structure model and observation) rejected as $\operatorname{CMIN}\left(\chi^{2}\right)=177.057$ and .000 probability[16].

Table 4. General Index for Measurement model

\begin{tabular}{|c|c|c|c|c|c|c|}
\hline General Index & CMIN(DF)/P & $\begin{array}{c}\text { Normed } \chi 2 \\
(\mathrm{CMIN} / \mathrm{DF})\end{array}$ & $\begin{array}{c}\text { Goodness of Fit } \\
\text { Index(GFI) }\end{array}$ & $\begin{array}{c}\text { Root MeanSquare Error of } \\
\text { Approximation } \\
\text { (RMSEA) }\end{array}$ & $\begin{array}{c}\text { Normed Fit } \\
\text { Index(NFI) }\end{array}$ & $\begin{array}{c}\text { Comparative Fit } \\
\text { Index(CFI) }\end{array}$ \\
\hline structure model & $140.920(75) / .000$ & 1.879 & .964 & .050 & .926 & .964 \\
\hline $\begin{array}{c}\text { Standard for } \\
\text { Validity }\end{array}$ & $\mathrm{p}>.05$ & $\leq 5.0$ & $\geq .90$ & $\leq .08$ & Adeq & $\geq .90$ \\
\hline Result & Inadeq & Adeq & Inadeq & Adeq & Adeq \\
\hline
\end{tabular}

Table 5. Overall index for the verification of the fitness of the structural model

\begin{tabular}{|c|c|c|c|c|c|c|}
\hline Overall Index & $\mathrm{CMIN}(\mathrm{DF}) / \mathrm{P}$ & $(\mathrm{CMIN} / \mathrm{DF})$ & $(\mathrm{GFI})$ & $(\mathrm{RMSEA})$ & $(\mathrm{NFI})$ & $(\mathrm{CFI})$ \\
\hline structural model & $279.880(84) / .000$ & 3.332 & .926 & .050 & .854 & .892 \\
\hline standard of fitness & $\mathrm{p}>.05$ & $\leq 5.0$ & $\geq .90$ & $\leq .08$ & $\geq .90$ & $\geq .90$ \\
\hline result & inconsistent & consistent & consistent & inconsistent & inconsistent & inconsistent \\
\hline
\end{tabular}

Table 6 . The validity evaluation of updated model

\begin{tabular}{|c|c|c|c|c|c|c|c|}
\hline Model & Modification & $\mathrm{CMIN}(\mathrm{DF}) / \mathrm{P}$ & CMIN/DF & GFI & RMSEA & NFI & CFI \\
\hline Modification Model & $\begin{array}{l}\text { removing insignificant path } \\
\text { covariate liberalization }\end{array}$ & $177.057(81) / .000$ & 2.186 & .934 & .040 & .908 & .947 \\
\hline $\begin{array}{l}\text { Comparing research model and } \\
\text { modification model }\end{array}$ & $\begin{array}{c}\chi^{2}=\chi 1^{2}-\chi 2^{2} \\
279.880-177.057=102.823 \\
d f=84-81=3\end{array}$ & $\nabla(\nabla)$ & $\nabla$ & $\triangle$ & $\nabla$ & $\triangle$ & $\triangle$ \\
\hline Result & & improved & adeq & adeq & adeq & adeq & adeq \\
\hline
\end{tabular}

Table 7. Verification of hypothesis

\begin{tabular}{|c|c|c|c|c|}
\hline Hypothesis & Path of Hypothesis & Path Coefficient & significance & result \\
\hline Hypothesis 1 & Structural Constraints $\rightarrow$ Iintrapersonal Constraints & .669 & .000 & selected \\
\hline Hypothesis2 & Internpersonal Constraints $\rightarrow$ Iintrapersonal Constraints & .203 & .004 & selected \\
\hline Hypothesis3 & Structural Constraints $\rightarrow$ motivation & .024 & .563 & rejected \\
\hline Hypothesis4 & Interpersonal Constraints $\rightarrow$ motivation & .117 & .200 & rejected \\
\hline Hypothesis5 & Intrapersonal Constraints $\rightarrow$ motivation & -.790 & .000 & selected \\
\hline Hypothesis6 & Leisure Motivation $\rightarrow$ Leisure Participation & .249 & .000 & selected \\
\hline
\end{tabular}

The value of CMIN(DF) is 2.816, and it shows that the structural model set in this study is mostly consistent. And the revision model turned out to be an exemplary model as the fitness index(GFI, RMSEA, NFI, CFI) appeared to be improved comparing to the study model. Therefore, the revision model was selected as the theoretical model of security agents' hierarchical leisure constraint, leisure motivation and participation in this study. 


\subsection{Verification of hypothesis}

The hierarchical leisure constraints of security agent showed to influence leisure motivation and leisure participation. To look more in concrete is with Table. 7 .

According to table 7, hypothesis 3,4 were rejected and hypothesis $1,2,5,6$ were selected. To suggest structure model on basis with Fig. 3 is as follows.

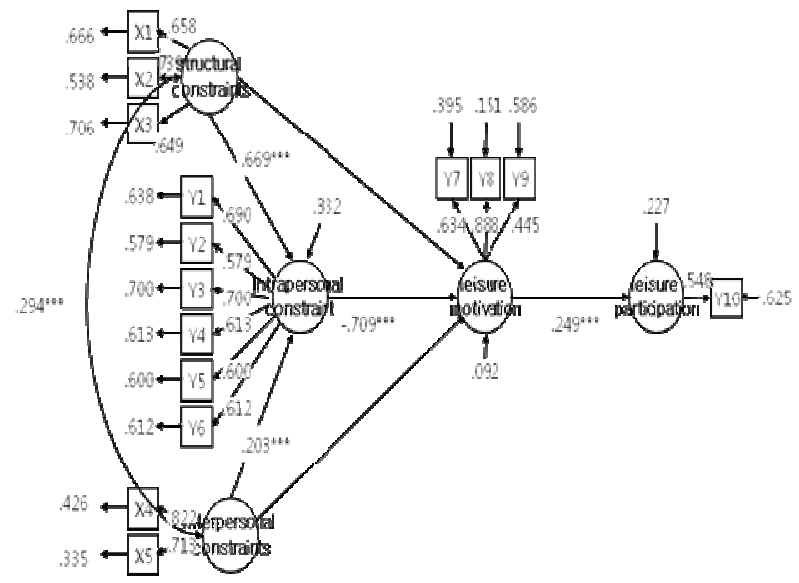

Fig. 3. Proposing Model for Hierarchical Leisure Constraints, leisure motivation, and participation of security agent

The causal effect of structural equation is classified as direct effect and indirect effect. The proceeding of indirect effect is: structural constraint $\rightarrow$ personal constraint $\rightarrow$ leisure motivation $\rightarrow$ leisure participation(.669×-709×.249=-.118) $\rightarrow$ intrapersonal constraint $\rightarrow$ leisure motivation $\rightarrow$ leisure participation $(.203 \times .-.709 \times .249=-.036)$. Total causal effect is the $\operatorname{sum}(.118-.036=-.154)$ of indirect effect.

\section{DISCUSSION AND CONCLUSION}

\subsection{Discussion}

Because this study considered only leisure motivation variable in relationship between leisure constraint and leisure participation of security staff, it did not control other extraneous variables. In recent studies of leisure constraint and leisure participation, effort variable to overcome leisure constraint (negotiation) along with leisure motivation were reported as important variable. In addition, this study has limit in generalizing study result to other districts by limiting research object in Seoul. Nonetheless, the result of this study can contribute to understanding leisure activities of security staff as research on leisure activities of security staff is very insufficient.

Meanwhile there have not been enough cases of research regarding the influence of security agents' hierarchical leisure constraint on leisure motivation and participation in the field of physical education. It is true that the research of the leisure in the aspect of welfare in the working environment of security agents who promote the security of the property and the body of the customers with the human resources. In this context, this study attempts to analyze the factors that affect the leisure participation by understanding the factors of security agents' hierarchical leisure constraint and the factors of leisure motivation. As a result of analysis, hierarchical constraint turned out to be influential in leisure motivation and participation. Here, the discussion proceeds around the statistically meaningful hypothesis.

First, as a result of analysis on the influence of structural leisure constraint on intrapersonal leisure constraint, structural constraint was found to affect intrapersonal leisure constraint. This result was attributable to the finding that the structural leisure constraint such as the cost, equipment required in attending leisure activities get larger, the intrapersonal leisure constraint gets larger as well. This finding is strongly supported by the study of Lee[3] who reported that the larger the structural leisure constraint, the bigger the intrapersonal leisure constraint. Looking into the working condition of security agents, their surrounding environment, monthly income etc. are relatively inadequate that other jobs, while workload is heavier. When security agents experience difficulties due to the structural constraint, the intrapersonal constraint becomes deepen. The improvement of welfare of the workers through shedding the manager-oriented working principles by expanding the cost of equipment, supporting exercise expenses, increasing leisure time, and improving income and working condition is desirable to overcome intrapersonal constraints.

Second, as a result of analysis on the effect of interpersonal leisure constraint on intrapersonal leisure constraint, it turned out that the interpersonal leisure constraint does have influence on the intrapersonal leisure constraint. This result indicates that when there is not a companion in performing leisure activities, or the companion is in the distance so that it is impossible to participate in leisure activities, the radius of the intrapersonal leisure constraint can be larger. The leisure activities in these days have transformed to the form of direct experience such as the participation in sports games from the form of indirect experience such as watching movies and sports games, but as the leisure activities of direct experience mostly can be conducted interpersonally rather than intrapersonally, the intensity of the intrapersonal leisure constraint can become heavier. And as the kinds of leisure activities become various, it is more probable for the security agents to be restricted regarding the cost, time, physical environment, and the companion who could join in conducting leisure activities. And the studies of Kang[17], Lee and Park[3] who reported that interpersonal leisure constraint is closely related to intrapersonal leisure constraint strongly support this result. To revitalize the participation of security agents in leisure activities, the intrapersonal leisure constraint should be minimized through solving the interpersonal leisure constraint. For it, government and relevant authorities should operate leisure education program for security staff in giving regular education. At present, leisure education is not included in regular education. Leisure education program should teach security staff how leisure activity participation is important in enhancing the quality of life and should encourage them to participate in leisure activity by motivating them. In particular, government and relevant authorities should develop various programs that encourage security staff to participate in group or interpersonal leisure activities instead of individual leisure activity and disseminate them. In addition, government and 
relevant authorities should improve working conditions so that security staff can participate in leisure activities more.

Third, as a result of analysis on intrapersonal leisure constraint on leisure motivation, personal leisure constraint turned out to negatively affect the leisure motivation. That is, if the intrapersonal leisure constraint increases, the leisure motivation goes down. This result suggests that when one is not accustomed to participating in the leisure activities with other people, or if there are any inconvenience using crowded facilities, or the personal and psychological constraints that come from being aware of other people's sight, lack of physical ability, or physical conditions, the motivation to participate in the leisure activities can be weakened.

This result corresponds to the assertions Jung[18], and Alexandris and Tsorbatzoudis[19] that personal constraint factor decreases leisure motivation. The fact that security agents' personal constraint affects the motivation to participate in leisure activities can be the obstacles both mentally and physically when personal factors take actions. Also the lack of physical activities triggered by the fear and psychological stress due to the lack of confidence can come along. Overcoming this kind of personal constraint can improve the environment that is the constraint factor both structurally and intrapersonally, and satisfy individual's psychological desire. This assertion is also supported by the research of Lee and Park[3] and others, and Loiser et al[20] which are based on the self-determination theory by Deci and Ryan[21] about the preposition that motivation can be affected through psychological intuitive process.

Fourth, as a result of analysis on the effect of leisure motivation on leisure participation, it was proved that leisure motivation does affect leisure participation. That is to say, when the leisure motivation gets higher, the proportion of participation gets higher as well. The results depend on the leisure motivation of individuals, and when motivation increases, participation increases too. Individuals' decisive perceptual ability decreases other constraint factors toward leisure participation, and it is also a main factor that settles the duration of participation in leisure activities[22][23][7]. By participating in leisure activities, security agents would be given excitement and pleasure, and it will lead to the decrease in stress level, and solidifying trust and unity with other people by maintaining that intrapersonal relationships. On the other hand, the results of leisure participation will show stark difference between the participation decided by oneself, or not. This result is supported by the research of Choi and Kim[24], Lee and Park[3], Ahn et al[25], Jung[18]. The ones who cultivate themselves through intellectual activities, sharing information and knowledge by participating in leisure activities, will enhance their motivation or desire of participating in leisure activities as they achieved confidence through the accomplishment than the people who did not. The experience of achievement is also needed by stimulating inner motivation and participating in leisure activities with desire[25]. The irregular working time, working condition, and constant work stress of security agents lessen the desire to participate in leisure activities. The managers should improve the working condition and welfare environment to let the security agents to actively participate in leisure activities and gain information and knowledge, along with cultivating one's abilities. In conclusion, the leisure constraint of security agents turned out to affect the vitalization of the participation in leisure activities through social awareness and irregular aspects of environmental factors, and this causes a direct influence of leisure constraint on leisure motivation. Therefore, in order to earn the growth of security firms and the success in management, the improvement of irregular working condition, and above all, leisure time should be increased by decreasing workload are needed. And that will lead to the psychological revitalization of security agents which will result in the improvement in productivity and business success. The mutual efforts will be required to drive away the misconception that leisure activities are wasteful and unproductive, to enhance the efficacy through leisure activities, and to accomplish selfrealization. The participation of security agents on leisure activities can be said to be the essential element in maintaining efficiency in the workplace, and in maintaining happy and prosper life.

\subsection{Conclusion}

The conclusions drawn from above research process focusing on the results of hypothesis verification are as follows.

First, structural leisure constraint positively affect intrapersonal leisure constraint. That is, the more the structural constraint, the more the intrapersonal constraint.

Second, interpersonal leisure constraint positively affect intrapersonal leisure constraint. That is the more the interpersonal leisure constraint, the more the intrapersonal leisure constraint.

Third, structural constraint does not affect leisure motivation.

Fourth, interpersonal constraint does not affect leisure motivation.

Fifth, intrapersonal leisure constraint negatively affect leisure motivation. That is, the more the personal constraint, the lower the leisure motivation.

Sixth, leisure motivation positively affects leisure participation. That is, the higher the leisure motivation, the higher the proportion of leisure participation.

Proposals for boosting leisure participation of security staff based on this study are as follows.

First, the policy to vitalize leisure should be arranged to overcome structural leisure constraints. Thai is to say, government and relevant authorities should encourage security staff to actively participate in leisure activities by expanding leisure time and supporting cost of leisure activities. Managers should aware that security staff's participation in leisure activities can contribute to self-actualization, self development and further improvement of management performance.

Second, government and relevant authorities should operate leisure education program to overcome intra personal leisure constraint. That is to say, leisure skill that enables security staff to enjoy leisure with family or coworkers should be developed. In addition, the program that security staff can participate in leisure activity with partners of leisure should also be developed.

Third, leisure activity campaign along with change in awareness of leisure activities should be developed to overcome internal leisure constraints of the individual. 
Government and relevant authorities should make security staff motivated for participation in productive leisure activities through campaign like sports 7330 for intrinsic motivation can act as strong mechanism that can encourage security staff to participate in leisure activities.

Those who manage security staff should aware that investment and support for leisure activities of security staff can contribute to improving productivity by relieving work stress, enhancing work concentration, job satisfaction and quality of life.

\section{REFERENCES}

[1] K.-S. Kim, P.-S. Kim, and C.-S. Kim, "Relationship between Leisure Constraints, Participation in Sports for Alland Subjective Happiness among Private Guards," The Journal of the Korea Contents Association, vol. 7, no. 12, 2007, pp.167-178.

[2] B.-W. Ahn, K.-J. Yi, J.-S. Lee, and J.-T. Kim, "The Influence of Leisure Constraint on Participation Motivation for Paragliding Participants," Journal of Leisure and Recreation studies, vol. 30, 2006, pp.225-236.

[3] Y.-L. Lee, and M.-S. Park, "The Causations among Leisure Constraints, Leisure Motivation, and Leisure Participation on the Ecological Perspective - Through the Construction of a Structural Equation Model," Journal of Korean Home Management Association, vol. 24, no. 1, 2006, pp.11-30.

[4] D.W. Crawford, E.L. Jackson, and G. Godbey, "A hierarchical model of leisure constraints," Leisure Sciences, vol. 13, 1991, pp. 309-320.

[5] J.C. Anderson, and D.W. Gerbing, "The effect of sampling error on convergence, improper solutions, and goodnessof-fit indices for maximum likelihood confirmatory factor analysis," Psychometrika, vol. 49, 1988, pp. 155-173.

[6] E.L. Jackson, "Recognizing patterns of leisure constraints: Results from alternative analyses," Journal of Leisure Research, vol. 25, 1993, pp. 129-149.

[7] M. Stodolska, "Changes in leisure participation patterns after immigration," Leisure Sciences, vol. 22, 2000, pp. 39-63.

[8] B. Carroll, and K. Alexandris, "Perecption of constraints and strength of motivation- Their relationship to recreational sport participation in Greece," Journal of Leisure Research, vol. 29, no. 3, 1997, pp. 279-299.

[9] L.A. Raymore, "Facilitators to leisure," Journal of Leisure Research, vol. 34, no. 1, 2002, pp. 37-51.

[10] K.-S. Kim, C.-S. Kim, K.-L. Lee, and P.-S. Kim, "Analysis of the Views on Leisure of Security Agents", The Journal of the Korea Contents Association, vol. 9, no. 1, 2009, pp. 388-399.

[11] W. Jennifer, and C.M. Roger, "Testing Competing Models of the Leisure Constraint Negotiation: Process in a Corporate Employee Recreation Setting," Leisure Sciences, vol. 23, 2001, pp. 145-163.

[12] G.-S. Jung, The Effects of a after school inclusive leisure program on ego- identity, leisure motivation and participation behavior of high school students with disabilities, doctoral dissertation, E-wha womans university, 2006.

[13] B.D. Wheatn, D.A. Muthen, and G. Summers, Assessing Reliability and Stability in Panel Models, Van Gorcum Sanfrancisco, 1977.
[14] S.-B. Jo, LESREL Structural Equation model, youngji Culture Press, Seoul, 1996.

[15] B.-J. Lim, and K.-S. Kim, "The Analysis of Structural Equation Modeling of Consumer Behavior in Spectator Sport," Journal of Korean Sociology of Sport, vol. 15, no. 1, 2002, pp. 31-45.

[16] K.G. JÖreskog, and D. SÖrbom, LISREL VII: Analysis of linear structural relationship by the method of maximum likelihood: user's guide, Scientific Software Inc., Illinois, 1998.

[17] S.-H. Kang, A study on the Factors Affecting of Restricting the Leisure, doctoral dissertation, Sungkyunkwan University, 1999.

[18] W.-J. Jung, and S.-B. Choi, "The Study on Leisure Constraints, Leisure Motivation, Leisure Participation of Leisure Participants," Journal of Leisure and Recreation studies, vol. 32, no. 3, 2008, pp. 133-142.

[19] K. Alexandris, and C. Tsorbatzoudis, "Perceived constrains on recreational sport participation: Investigating their relationship with intrinsic motivation, extrinsic motivation and amotivation," Journal of Leisure Research, vol. 34, no. 3, 2002, pp. 233-252.

[20] G.F. Loiser, P.E. Bourque, and R.J. Vallerand, "Amotivational model of leisure participation in the elderly", Journal of Psychology, vol. 127, no. 2, 1993, pp. 153-170.

[21] E.M. Deci, and R.L. Ryan, Intrinsic motivation and selfdetermination in human behavior, Plenum Press, New York, 1985.

[22] E.L. Jackson, "Leisure constraints/constrained leisure Special issue introduction," Journal of Leisure Research, vol. 23, 1991, pp. 279-285.

[23] R. Kanfer, The blackwell dictionary of organizational behavior. Blackwell Publishers, Oxford, UK, 1994.

[24] S.-H. Choi, and C.-W. Kim, "Analysis of participating motivation, exercise adherence, and adherence intention of college tennis dub members," The Korean Journal of Physical Education, vol. 43, no. 2, 2004, pp. 831-844.

[25] H.-K. Ahn, P.-S. Kim, and C.-S. Kim, "Relationship between Leisure Motivation of Private Guards and Sports Participation," The Journal of the Korea Contents Association, vol. 8, no. 3, 2008, pp. 225-233.

[26] H. Lee, and Y.-M. Song, "Analysis on the leisure facilitator's factors and leisure participation", Paper presented in Congress of the $55^{\text {th }}$ Korean Society for the Tourism, 2004.

[27] H, Lee, C. Chung, R.-S. Chung, S.-G. Lee, and W.-C. Chung, "Structural equation model of leisure activities \& constraints - Based on PPA \& Leisure constraints theory", Journal of Tourism and Leisure, vol. 16, no. 2, 2004, pp. $29-48$.

[28] I.-J. Lee, and H. Lee, "A critical review of constraints studies in leisure literature", Journal of Korean Tourism, vol. 30, no. 4, 2006, pp. 339-357.

[29] R.-S. Chung, H. Lee, and I.-J. Lee, "The critical remodeling leisure constraints: Integrating social structure and individual action", Journal of Korean Tourism, vol. 31, no. 1,2007 , pp. 55-75. 


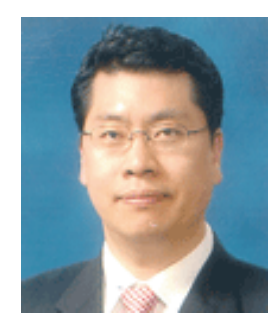

\section{Kyong-Sik Kim}

He received the B.S., in a department of Sport and Leisure Studies from Kyonggi university., Korea in 1994 and M.S., Ph.D. in department of Physical Education from Seoul university, Korea in 1996, 2004.

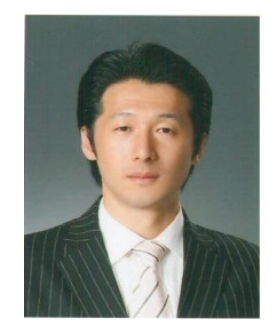

\section{Young-Man Park}

He received the B.S. in a department of safety management Korea National Sport University., Korea in 2002 and received M.S. in a safety management from Korea National Sport university, Korea in 2006, Since then, He has been Ph.D. Candidate in Protection and Security Administration from Kyong-gi university, Korea in 2010. 